\title{
Surface Roughness Intelligent Prediction on Grinding
}

\author{
Dingtong Zhang ${ }^{1,}$, Ning Ding ${ }^{2, b^{*}}$ \\ ${ }^{1}$ Jilin Province Agriculture Machine Research Institute, Changchun 130022, China \\ ${ }^{2}$ College of Mechanical Engineering, Changchun University, Changchun 130022,China \\ aglamorous_tong@sohu.com, ${ }^{b} \mathrm{dn} 33 \mathrm{cn} @ 163 . c o m$
}

Keywords: grinding, surface roughness, prediction, fuzzy neural network, AE

Abstract. Grinding is generally the final process, and it is closely related with the surface quality of the component. Now, it's difficult to measure the surface roughness until the grinding process is finished. The purpose of this research was to study the roughness prediction and avoid the defect happening in the grinding process. A surface roughness prediction model was built using the acoustic emission (AE) signal and Fuzzy- neural networks. Tests were performed, and the result verifies the feasibility of the proposed model.

\section{Introduction}

The grinding operation gives workpieces their final finish surface roughness through the interaction between the abrasive grains of grinding wheel and the workpiece. However, Grinding process is non-linear, random and indeterminate, and it's difficult to build exact mathematic model. Now, all the existing measuring methods can't be conducted until the grinding process is finished. This means following problems will occur: time, labor, and material have to be spent continuously after a defect happens in the grinding process; the measured results are not the current surface quality information, which are needed in the modern manufacturing process. To settle this problem, many experts studied the roughness and built some surface roughness theory models and experimental models [1-6], but their accuracy is low and can't widely apply in the practice grinding process.

In this paper, we propose an intelligent roughness prediction model based on acoustic emission (AE) signals, in which not only the grinding parameters but also the AE signals are added to the inputs.

\section{Intelligent Predication Model's Building}

Theory Basis. Extensive studies have been carried out in the workpiece surface roughness for the grinding process. For cylindrical traverse grinding, Malkin developed a surface roughness theory equation as follows [7]

$$
\mathrm{R}_{\mathrm{a}}=\left(\frac{\mathrm{R}_{0}}{\mathrm{~m}^{1 / 2}}\right)\left(\frac{\mathrm{v}_{\mathrm{w}} \mathrm{L}}{\mathrm{v}_{\mathrm{s}} \mathrm{d}_{\mathrm{e}}^{1 / 2}} \cdot \frac{\mathrm{f}_{\mathrm{a}}}{\mathrm{b}_{\mathrm{s}}}\right)^{0.8}+\mathrm{R}_{\infty}
$$

Here, $R_{0}$ and $R_{\infty}$ are experience constants respectively; $\mathrm{m}$ is a constant ; $\mathrm{v}_{\mathrm{w}}$ is the workpiece velocity; $\mathrm{V}_{\mathrm{s}}$ is the grinding wheel velocity; $\mathrm{L}$ is the grain uniformity distribution distance along the grinding wheel circumference; $d_{e}$ is the grinding wheel diameter; $f_{a}$ is the table feed $; b_{s}$ is the grinding wheel width. Eq. 1 was obtained under the ideal condition without principal axis jumpiness, vibration and plastic deformation, and actual roughness value will be much bigger than that. But the theory equation is useful in analysis the relations between the surface roughness and grinding parameters. From Eq.1, we get that roughness is in direct proportion to workpiece velocity $v_{w}$ and table feed $f_{a}$, and in inverse proportion to grinding wheel velocity $\mathrm{v}_{\mathrm{s}}$.

Literature [8,9] indicates that the surface roughness data are apt to obey the following. 


$$
\mathrm{R}_{\mathrm{a}}=\mathrm{R}_{1}\left(\frac{\mathrm{v}_{\mathrm{w}} \mathrm{a}_{\mathrm{p}}}{\mathrm{v}_{\mathrm{s}}}\right)^{\mathrm{x}}
$$

Where, $\mathrm{R} 1$ and $\mathrm{x}$ are, respectively, the constants determined by the experiment. ap is grinding depth. From Eq.2, we get that the roughness is in direct proportion to grinding depth ap .

Since the wear of the grinding wheel has a direct effect on the workpiece surface roughness, the signal of acoustic emission can show the wear degree of grinding wheel.

Considering all of the above relationships, we proposed the relations of roughness and machining parameters as follows

$$
\mathrm{R}_{\mathrm{a}}=\mathrm{R}\left(\frac{\mathrm{v}_{\mathrm{w}}}{\mathrm{v}_{\mathrm{s}}}\right)^{\mathrm{x}} \quad\left(\mathrm{a}_{\mathrm{p}}\right)^{\mathrm{y}}\left(\mathrm{V}_{\mathrm{f}}\right)^{\mathrm{z}} \mathrm{W}_{\mathrm{AE}}
$$

Where, $\mathrm{R}, \mathrm{x}, \mathrm{y}, \mathrm{z}$ are experimental constants respectively. WAE is the wear degree of grinding wheel. This relationship is the theory basis of our proposed roughness prediction model in this paper.

Architecture and Algorithm. In Eq.3, R, x, y, z and $\mathrm{m}$ are the experimental constants, which are on the case-by-case basis. The values of $\mathrm{R}, \mathrm{x}$, and $\mathrm{y}$ established under one grinding condition generally cannot be used for roughness prediction of other conditions. To settle the problem, the fuzzy neural network is introduced in modeling process, because the fuzzy neural network has self-learning and self-adapted ability. In this fuzzy neural network, the neural network is used to implement fuzzy inference. The parameters in fuzzy inference are expressed with neural network connection weights. Eq. 3 is calculated logarithm in the two sides. Supposing $\operatorname{lgR}=\mathrm{R} 1$, we can get the following.

$$
\lg R_{a}=R_{1}+x \lg \left(\frac{v_{w}}{v_{s}}\right)+y \lg a_{p}+z \lg V_{f}+\lg W_{A E}
$$

We use the logarithm of the velocity ratio of (vw/vs), the logarithm of grinding depth ap, the logarithm of traverse feed velocity fa and the logarithm of wear degree of grinding wheel WAE as inputs of fuzzy neural network, and the logarithm of the roughness is as the output, shown in Fig.1.

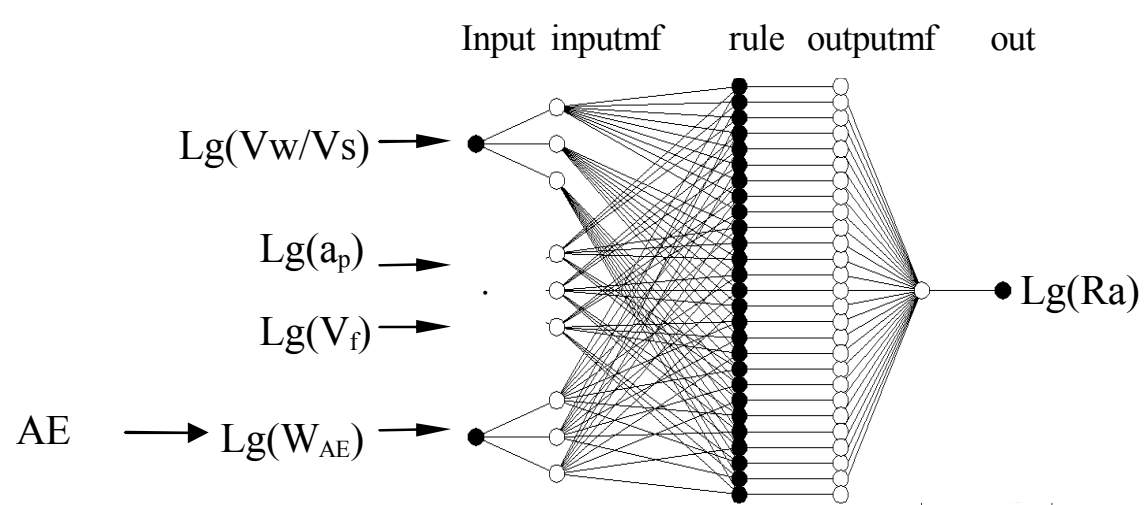

Fig.1 Architecture of the fuzzy neural network based on AE

From the Eq. 4, we know that there exists linear relation between the roughness logarithm and the logarithm of (vw/vs), ap, fa and WAE. So, we adopt T-S type fuzzy inference to obtain R1, x, y and $\mathrm{z}$. The rule form is as followings: If $\mathrm{x} 1=\mathrm{A} 1, \mathrm{x} 2=\mathrm{A} 2, \mathrm{x} 3=\mathrm{A} 3$, then $\mathrm{fj}=\mathrm{pj} \mathrm{x} 1+\mathrm{qj} \times 2+\mathrm{rjx} 3+\mathrm{sj}$ 


\section{Experiment}

The experiments had been finished on the MGK1420 high precision CNC cylindrical grinder. The signals of acoustic emission were collected and analyzed by Beijing Shenghua SAEU2S system, and the sensor is SR800. The grinding liquid is emulsion. The wheel's dressing depth and lead are $0.01 \mathrm{~mm}$ and $0.08 \mathrm{~mm}$ respectively. The material of the workpiece is 45 steel.

The main grinding parameters vw, vf and ap related to the roughness can be changed by this experimental grinder. The experiment was finished with workpiece velocity ${ }_{w} 125 \mathrm{r} / \mathrm{m}, 170 \mathrm{r} / \mathrm{m}$ and $200 \mathrm{r} / \mathrm{m}$, table feed fa $6 \mathrm{~mm} / \mathrm{r}, 9.6 \mathrm{~mm} / \mathrm{r}, 13.6 \mathrm{~mm} / \mathrm{r}, 17.6 \mathrm{~mm} / \mathrm{r}, 21.6 \mathrm{~mm} / \mathrm{r}$ and $26.8 \mathrm{~mm} / \mathrm{r}$, and grinding depth ap $0.01 \mathrm{~mm}, 0.02 \mathrm{~mm}$ and $0.03 \mathrm{~mm}$, respectively. The workpiece surface roughness $\mathrm{R}$ was measured with surface roughness detector TR240. We obtained 90 specimen groups, among which, 60 specimen groups were used to train the fuzzy neural networks, and 30 specimen groups were used to test the fuzzy neural networks.

Table 1 shows the roughness results of the fuzzy neural network predictive model and actual measurement. It can be seen from Table 1 that the prediction roughness results of the proposed fuzzy neural network predictive model with $\mathrm{AE}$ in this paper are very close to the measured one.

Table 1 Roughness result of the intelligent prediction model $(\mathrm{Ra} \mu \mathrm{m})$

\begin{tabular}{|l|c|c|c|c|c|c|c|c|c|c|}
\hline & 1 & 2 & 3 & 4 & 5 & 6 & 7 & 8 & 9 & 10 \\
\hline $\begin{array}{l}\text { Measure } \\
\text { value }\end{array}$ & 0.092 & 0.121 & 0.113 & 0.130 & 0.074 & 0.101 & 0.103 & 0.107 & 0.118 & 0.148 \\
\hline $\begin{array}{l}\text { Prediction } \\
\text { value }\end{array}$ & 0.090 & 0.117 & 0.109 & 0.131 & 0.080 & 0.100 & 0.107 & 0.107 & 0.118 & 0.137 \\
\hline $\begin{array}{l}\text { Relative } \\
\text { error }\end{array}$ & -0.024 & -0.033 & -0.034 & 0.002 & 0.074 & -0.007 & 0.033 & -0.001 & 0.001 & -0.076 \\
\hline
\end{tabular}

\begin{tabular}{|l|c|c|c|c|c|c|c|c|c|c|}
\hline & 11 & 12 & 13 & 14 & 15 & 16 & 17 & 18 & 19 & 20 \\
\hline $\begin{array}{l}\text { Measure } \\
\text { value }\end{array}$ & 0.126 & 0.149 & 0.161 & 0.193 & 0.043 & 0.172 & 0.168 & 0.210 & 0.047 & 0.126 \\
\hline $\begin{array}{l}\text { Prediction } \\
\text { value }\end{array}$ & 0.127 & 0.152 & 0.160 & 0.191 & 0.042 & 0.172 & 0.167 & 0.211 & 0.046 & 0.125 \\
\hline $\begin{array}{l}\text { Relative } \\
\text { error }\end{array}$ & 0.015 & 0.023 & -0.003 & -0.013 & -0.007 & 0.003 & -0.006 & 0.008 & -0.018 & -0.009 \\
\hline
\end{tabular}

\begin{tabular}{|l|c|c|c|c|c|c|c|c|c|c|}
\hline & 21 & 22 & 23 & 24 & 25 & 26 & 27 & 28 & 29 & 30 \\
\hline $\begin{array}{l}\text { Measure } \\
\text { value }\end{array}$ & 0.141 & 0.174 & 0.169 & 0.170 & 0.062 & 0.080 & 0.099 & 0.093 & 0.101 & 0.125 \\
\hline $\begin{array}{l}\text { Prediction } \\
\text { value }\end{array}$ & 0.143 & 0.171 & 0.171 & 0.172 & 0.060 & 0.082 & 0.101 & 0.093 & 0.104 & 0.125 \\
\hline $\begin{array}{l}\text { Relative } \\
\text { error }\end{array}$ & 0.009 & -0.016 & 0.010 & 0.010 & -0.023 & 0.022 & 0.023 & 0.003 & 0.029 & 0.006 \\
\hline
\end{tabular}

The correctness and coverage of the training data affect the model accuracy directly since the accuracy of proposed prediction model depands on training data.

\section{Conclusion}

This paper builds the intelligent predictive model of surface roughness in grinding process based on AE. The experimental results prove that the proposed fuzzy neural networks prediction model based on AE is feasible and have higher prediction accuracy. 


\section{Acknowledgements}

The authors are thankful the financial aid to this project supported by Industrial Technology Research and Development Projects of Jilin Province in China ([2013]779).

\section{References}

[1] Bhateja, C.P.( 1977)An Enveloping Profile Approach for the Generation of Ground Surface Texture. Annals of the CIRP, Vol.25, No.1,p.333-338.

[2] Fletcher, N.P.( 1980) A Simple Model for Predicting the Possible Surface Roughness of a Cylindrically Traverse Ground Workpiece when Using Wheels Dressed with Single Point Diamond Tools. Proceedings of the Twenty-first International Machine Tool Design and Research Conference. p.329-337.

[3] Banerjee, J.K. and Hillier, M.J.(1972)Some Observations on the Effects of Wheel Wear Land on Workpiece Surface Finish during Flat Surface Grinding with Cross-Feed. First World Conference on Industrial Tribology, New Delhi.p.5-11.

[4] Vicherstaff,T.J.(1973) Wheel Wear and Surface Roughness in Cross Feed Surface Grinding . Int. J. Mach. Tool Des. Res, Vol.13.p.183-189.

[5] Y.C. Shin, S.J. Oh and S. A. (1977)Coker. Surface Roughness Measurement by Ultrasonic Sensing for In-Process Monitoring. Journal of Engineering for industry. p. 439-447.

[6] Zhou X, Xi F. (1999) Modeling and Prediction Surface Roughness of the Grinding Process. International Journal of Machine Tools \& Manufacture. Vol.1, No.39.p.1451-1470.

[7] S. Malkin. Theory and Application of grinding technology. 2002.p.10.

[8] Snoeys, R., Peters, J.and Decneut, A. (1974)The Significance of Chip Thickness in Grinding. Annals of the CIRP.Vol.23,No.2. p.227-332.

[9] Kedrov, S.M.(1980)Investigation of Surface Finished in Cylindrical Grinding Operations. Machines and Tooling. Vol.51,p.40-45. 